\title{
Performance Management as an Alternative Tool for Local Governance: Evidence from Ghanaian Local Government Sector
}

\author{
Juliana Abagsonema Abane \& Boon-Anan Phinaitrup \\ National Institute of Development Administration (NIDA) \\ Graduate School of Public Administration (GSPA), Ghana \\ E-mail: abanejulie@gmail.com
}

Received: July 12, 2017 Accepted: July 25, 2017 Online published: August 4, 2017

doi:10.5296/ijhrs.v7i3.11532ＵRL: https://doi.org/10.5296/ijhrs.v7i3.11532

\begin{abstract}
The benefit of performance management is to have value for money and make local authorities more responsive to the needs of the grassroots. Therefore, the study addresses the perceived challenges which have been taken-for-granted in institutionalising performance culture at the local level in the context of sub-Sharan Africa. The purpose of this research is to investigate the progress and challenges affecting the institutionalisation of performance management in local government authorities to understand how these impediments impacts on performance culture in local governance. Using two major secondary data sources from Local Government Service, the study analyzes the contents of four key performance areas and the performance rating of local government authorities in Ghana. The study finds evidence to support that performance management may be an alternative tool to enhance the performance of local authorities. However, insufficient resource allocation, the absence of performance improvement programs and involvement of employees remains a challenge.
\end{abstract}

Keywords: Local Government Key Performance Areas, performance management, challenges, alternative management tool, Ghanaian Local Government Sector, MMDAs

\section{Introduction}

Performance Management (PM) is a next-generation tool for managing people in all types of organizations, however, it is not without controversies (Fryer et al., 2009; Heinrich 2007; Radin, 2006). PM generates much tension in public organizations than the private sector in part because the performance doctrine has inherent contradictions in public service ethos (Radin 2006). The concept of PM is a strategic human resource management tool for 
managing employee and organizational performance (Aguinis et al., 2012; Ashdown, 2014; Armstrong and Baron 1998). For the purposes of this study, PM refers to a holistic approach to people management towards improving employee performance to help an organization achieve human resource outcomes such as competence, commitment, congruence and cost-effectiveness. PM process recognises three distinctive stages, strategic orientation, human resource and developmental activities (Armstrong and Baron, 1998).

Undoubtedly, designing an effective PM in local government institutions may help reduce uncertainty of local level service delivery, however, it is the single most important challenge facing local government entities and central government agencies in this era (Ammons and Roenigk, 2015; Baird et al., 2012; Nurkholis et al., 2014). It is difficult to explain if PM affects organizational performance, yet, research suggests that some public and local government authorities can improve their service delivery through PM initiatives (Brignall and Modell 2000; Waal and Counet, 2009). The adoption of the concept in public sector organizations is that it reduces waste and ensures value for money practices (Ter Bogt, 2008). Other studies have found evidence to support that PM initiatives have failed to deliver efficient service in government organizations (Fryer et al., 2009). However, a good number of studies on PM is bourgeoning and most public organizations have pursued the performance regime with rigour (Bouckaert and Halligan, 2008; Kroll and Proeller, 2013; Rhodes et al., 2012). Notwithstanding, there are inherent challenges that local and central government agencies face in trying to design and implement performance policies (Karuhanga, 2010). Yet this scenario suggests that governments must diagnose the problems and allocate resources, gain the commitment of employees and built their capacity to deliver public services.

In the last three decades, PM research have largely focused on the content (Moynihan, 2013; Bouckaert and Halligan, 2008; Rhodes et al., 2012), goal-orientation in central government agencies performance (Caillier, 2014; Hammerschmid et al., 2013; Latham et al., 2008), measurement system (Cavalluzzo and Ittner, 2004; Bourne, 2005; De Lancer Julnes, 2006; Bourne et al., 2014). However, there is limited research that examines the success and challenges of local governments PM objectives (Rogers, 1990; Sanderson, 2001; Ammons and Roenigk,2015). To date, studies explain local governments' PM through management control process, goal and measurement clarity, citizen participation, managerial responses and low-performance data use for decision making (Pollitt and Bouckaert, 2004; Yang and Hsieh, 2007; Moynihan and Lavertu, 2012). This is troubling because there are other areas such as the developmental aspect, the resource capacity of organizations which affect performance indicators have received less attention in the literature (Heinrich, 2007). The plausible reason for this type of focus in the literature may be that goal setting and strategic planning has direct effective on performance (Latham et al., 2008; Ammons and Roenigk, 2015). However, quantitative measurement tells us little about what challenges affect the outcomes of PM goals.

By studying the challenges that local government authorities experience during the implementation process, it may address the failure rates of government programmes at the local level. In addition, within the context of Ghana, there are a limited number of studies that 
focus on explaining the progress and challenges of local governments PM systems. Also, the institutionalisation of PM in local governance is relatively new (Local Government Service, 2016b). Although PM research is not new in Ghana, the focus is usually at central agencies and state-owned enterprises (Dodoo, 1997; Mnieh et al., 2011; Bawole et al., 2013; Simpson and Buabeng, 2013). These studies focus on the content and design of the PM policies without paying much attention to the implementation process. There are two main research questions of this study, what is the state of local governments PM systems? And what are the challenges if any, that impede local governments performance reforms? More specifically this study addresses how local governments have fared in their performance evaluation results, what are their successes and challenges that they face in implementing their PM policies at the local level.

The contribution of this paper is threefold. First, the paper directs the attention to local governments PM systems in Ghana. Second, by focusing on the challenges which confront local governments' performance constraints, policymakers would become aware of them and do something to support local authorities' efforts in maintaining a performance culture. And third, the paper demonstrates that the challenges have implications for governance and the need to address them by adopting pragmatic strategies through resource allocation and capacity building to achieve desired outcomes of the country's PM policy in general.

The study used secondary data sources from performance evaluation of metropolitans, municipals and districts assemblies (MMDAs) for 2016 and annual performance reports by the Local Government Service (LGS). Similarly, the public service PM policy for 2012 from the Public Services Commission (PSC) database was utilised to augment the analysis. To explain the theoretical underpinnings of institutionalising local government PM, the institutional theory was used to explain the conceptual basis for which performance culture is necessary for organizations (Brignall and Modell, 2000; Cavalluzzo and Ittner, 2004; Christensen et al.,2006). The results indicate that insufficient resource allocation, low commitment and capacity of chief executives, directors and staff in the implementation of PM contracts are the most serious challenges affecting MMDAs performance indicators. In terms of the achievement of the PM framework for local governance, almost half of the 216 MMDAs had an average score of 80 percent or above in their key performance areas. The remainder of the paper would briefly review existing body of knowledge, the theoretical basis of institutionalising PM. The analysis of the results of the secondary data, discussions and the conclusions are presented as well.

\section{Literature Review}

PM is a strategic tool for management of organizational workforce (Armstrong Baron, 1998), a developmental approach to employees' performance (Biron, Farndale, and Paauwe 2011; Maley 2014) and performance improvement (Furnham, 2004; Lee,2005). PM is designed to measure individual and organisational performance by setting output and outcomes standards ( Grizzle, 2002; Ammons and Rivenbark, 2008). PM is defined as a process of managing individual and organizational performance (Armstrong and Baron, 1998), economic rationality for ensuring efficiency and effectiveness (Ter Bogt, 2008). 
Research indicates that an effective PM is through goal setting (Ammons and Roenigk, 2015; Latham et al., 2008) and development of results-oriented performance measures (Taylor andTaylor, 2014; Cavalluzzo and Ittner, 2004).

Regardless of these assertions that PM ensures efficiency and effectiveness, available evidence reveals that it is less effective in public sector service delivery (Fryer et al., 2009). Yet there is little evidence to suggest why this is the case (Hvidman \& Andersen, 2014; Upadhaya et al., 2014) and whether these challenges may affect the achievement of local and central government agencies performance goals. Past research on PM focuses on the goals and measurement systems, the content, environmental influence and managerial responses (Hoontis and Kim, 2012; Latham et al., 2008; Newcomer, 2007; Yang and Hsieh, 2007). However, few studies have examined why the challenges persist (Fryer et al., 2009). Ohemeng (2011) and Kim \& Kang (2016) note that there are several problems which tend to affect the legislation of PM in organisations and some structural problems are most significant because they only focus on measuring and improving technical quality while the quality of the inputs and outcomes of organisational goals are downplayed (Kim and Kang, 2016). This implies that there might be a systemic issue related to the challenges and the uncertainty that affect PM implementation in local government agencies (Ammons and Roenigk, 2015).

However, the context of PM differs among countries (Bouckaert and Halligan 2008) and the national culture (Aguinis et al., 2012). By examining the success and the challenges of PM, this study hopes to see what these differences mean in the context of a developing country's institutionalisation of PM. It is useful to note that there are limited studies explaining the challenges and performance of local government authorities (Ammons and Roenigk, 2015; Baird et al., 2012; Rogers, 1990; Sanderson, 2001). In addition, most of these studies focus on the content, goals and performance measurement systems (Kim and Kang, 2016). By concentrating on the content of PM objectives, they tend to ignore the quality of the input process (Conaty, 2012). The assumption is that an organisation can achieve its economic rationality through clear goals and measurement without emphasising the inputs that may impede the intended PM objectives. More importantly, factors such as resource allocation (Heinrich, 2007), the low capacity of public managers (Kroll and Moynihan, 2015), poor attitudes of employees (Pollitt and Bouckaert, 2004; Rhodes et al., 2012; Yang and Hsieh, 2007) and employee involvement (Biron et al., 2011) in the PM implementation might explain why some local governments perform better than others.

The study aims to discover the possible challenges that might impact on local governments' performance policies and how the problems affect their key performance areas (KPAs). Evidence indicates that there are structural and technical challenges that might explain the differences in the performance evaluation of government agencies. In a study of Healthcare providers in South Korea, Kim and Kang (2016), found that health care providers focus more on measuring and improving technical goals while less emphasis is given to service quality. Kim and Kang's study suggests that with the legislation of health care services PM policies, the emphasis is towards achieving their key performance indicators (KPIs) which are measurable while unmeasurable aspects like outcomes of health service are neglected. 
Ohemeng (2011) study also found that the failure of the public service PM reforms was due to non-availability of a legislative framework to bind employees to induce behavioral change. However, other studies suggest that institutionalising PM in public organisations, may not result in improved performance (Annan-prah and Ohemeng 2015; Cavalluzzo and Ittner 2004; Nurkholis et al. 2014; Rhodes et al. 2012). Similarly, Fryer et al. (2009) found that technical, attitudinal behavior of public managers affects the outcomes of PM objectives. The difficulty in institutionalising PM is that there are other problems that present unique cases for some local government authorities to achieve their key results areas especially with regards to resource endowments, management capacity and the behavior of employees (Pollitt and Bouckaert,2004; Heinrich, 2007; Kroll and Moynihan, 2015).

As stated above, the literature on PM has largely focused on reporting the content, goal-setting process, the measurement system and performance information use. Other aspects include action planning, stakeholder participation, political actors behavior and managerial attitude and use of performance data (Moynihan and Pandey, 2010; Ammons and Roenigk, 2015; Baird et al., 2012; Conaty, 2012; Pollitt and Bouckaert, 2004; Rogers, 1990). These themes generally isolate the challenges associated with institutionalising PM systems (Ohemeng, 2011). Also, to date, in the Ghanaian local government sector, there is little information on the state of PM reforms in this sector. Despite, the adoption of PM policies for management in the country at the local level (Akudugu, 2013), little emphasis is paid to the loose ends of the performance of local government institutions.

Further, apart from Akudugu (2013) and Bawole et al. (2013), little is known, for instance, whether local government authorities PM have fared better than other central government agencies and the civil service performance regime as the country attempts to institutionalise performance culture in the public sector. To achieve value for money and best managerial practices, the adoption of new public management (NPM) reforms in the public service have been phenomenal (Annan-prah and Ohemeng, 2015; Ayee, 2001; Domfeh, 2004; Ohemeng, 2009; Rhodes et al., 2012; Simpson and Buabeng, 2013). Therefore, this study examines the results of MMDAs PM and the challenges if any that they are confronted with in their efforts to institutionalise performance culture in local governance. The next section outlines the theoretical assumptions which help to explain how PM systems are adopted and implemented in local government institutions in the analysis of this study.

\subsection{Theoretical Assumption: The Institutional Theory}

The institutional theory holds that the structuring of organisations and the homogeneity of diverse organisations are influenced by resource uncertainty, goal ambiguity, technical uncertainty and professionalisation by members (DiMaggio and Powell, 1983). DiMaggio and Powell focus on three institutional change process that organisations are affected by the actions of isomorphism. There are three forms of isomorphism, coercive, mimetic and normative. The processes of change in organisational fields go through the procedures which may become normalised, meaningful and then transmitted to new organisational members and shared without any question or thought (Brignall and Modell, 2000). Once the process of institutionalisations takes place, organisations become immortal and pursue changes that 
may not be in line with the organisational goals but the adoption of new practices to survive in the environment (DiMaggio and Powell, 1983).

The use of institutional theory helps us to explain how PM or human resource practices are adopted as a response to external pressures to minimise uncertainty that the environment of local government authorities present (Oliver, 1991; Cavalluzzo and Ittner, 2004; Brignall \& Modell, 2000). It helps us to understand how organisations adopt management practices into their internal business process either through coercive, normative and mimetic pressures that are external to the organisations (Brignall and Modell 2000; Cavalluzzo and Ittner, 2004; Ter Bogt, 2008). The institutional theory is used in the literature to explain how organisations often adopt performance practices in their day-to-day activities for easy management of individual and organisational performance (Brignall and Modell, 2000; Christensen et al., 2006). Therefore, the link between institutional perspective and PM indicate that government organisations tend to adopt performance reforms for regulatory requirement by an external force such as the government or an agency with full governmental power (Brignall and Modell, 2000; Cavalluzzo and Ittner,2004; Nurkholis et al., 2014).

The institutional theory attempts to explain how organisations survive by relying on take-for-granted practices which are transmitted to new organisational members with the aim of surviving external pressures (Cavalluzzo and Ittner, 2004; Ohemeng, 2011). When organisations are faced with strong external pressures, they go through the processes of isomorphism to contain the pressures pushing them to adapt the environment (Oliver, 1991). To understand why some management reforms are implemented and adopted by local authorities, the institutional theory focuses on the process of implementing government regulations in which organisations have non-choice behaviour (Nurkholis et al., 2014; Oliver, 1991). The important aspect of institutionalising PM is that, they come from external pressures and organisations have little to decide on them (Cavalluzzo and Ittner, 2004; Nurkholis et al.,2 014). However, it is unclear whether these practices are used in their internal business practices if they emerge from coercive powers (Cavalluzzo and Ittner, 2004; Ter Bogt, 2008). Cavalluzzo and Ittner (2004), found that normative practices of organisations help to explain why some reforms are adopted and implemented as they response to change for survival. As noted earlier, the institutional theory focuses on the normative, coercive and mimetic processes that organisations go through to contain the external pressures from their environment through the process of institutionalisation (Ohemeng, 2011).

The question of whether institutionalising PM is effective and organisations adopt them in their internal processes to satisfy regulatory requirements or fads are inconclusive (Brignall and Modell 2000; Cavalluzzo and Ittner, 2004; Nurkholis et al., 2014). However, there are enough studies to suggest that government organisations have adopted and implemented performance reforms because of institutionalisation processes in public institutions (Christensen et al., 2006).

Even though the institutional theory focuses on how change occurs in organisations, it is unable to indicate what kind of challenges that the processes of institutionalising PM reforms 
may have on central and local government organisations (Heinrich, 2007; Fryer et al., 2009). The resource scarcity of organisations also compels them to adopt these reforms to meet budgetary allocations for programs implementation (Heinrich, 2007). There are several factors that may compel local government institutions to adopt PM systems, to acquire resources, to maintain their reputation and secure legitimacy (Oliver, 1991). In addition, organisations may need to build their technical capacities by adopting these practices (Yang and Hsieh, 2007; Kroll and Moynihan, 2015). However, resources are not readily available and sometimes, they are hard to reach by deprived local government authorities. Subsequently, studies on the challenges facing PM indicate that low technical capacity (Kroll and Moynihan, 2015), insufficient budgetary allocation (Heinrich, 2007; Ohemeng, 2011), lack of ownership of PM goals (Van Dooren, 2011; Bawole et al., 2013) and poor attitudes of employees and senior managers (Pollitt and Bouckaert, 2004).

The aim of drawing on the institutional theory is to explain how the institutionalization of PM by local governments lead to problems which may affect the performance results of their key results areas (KRAs). It is important to note that adopting PM systems in local governance, there is the tendency to downplay the unique problems each of these entities face by policymakers who may expect the same level of results on policy programmes outcomes.. However, once we understand that the resource endowments either in material or human resources may impact on their performance, we may take steps to mitigate the effects of resource scarcity. This means that local governments should be assessed in the face of their unique problems in their efforts to adopt PM practices in their internal business processes. Consequently, studying the institutionalisation of PM in local governments, this study would be able to analyse the challenges that local governments are confronted with and draw on the steps taken by governments to institutionalise performance culture in Ghana (Ohemeng, 2011).

\subsubsection{Institutionalizing Local Government PM in Ghana.}

PM aim in public organisations is to ensure government responsiveness through a scientific method of obtaining information through KPIs to aid decision making in government programs, funding issues, and general human resource management (Heinrich, 2007). The experimentation with performance-related reforms shows six features of the new public management (NPM) reforms (Domfeh, 2004; Ohemeng, 2011; Simpson and Buabeng, 2013). For example, market-orientation, efficiency, effectiveness, performance-based results, transparency and accountability practices have been implemented in the public sector (Ayee, 2001; Mmieh et al., 2011)

The purpose of these reform initiatives was to ensure that government organisations deliver on rational economic goals of government and make public managers more accountable in the use of public resources. Research indicates that the attempt to institutionalise performance culture dates backs to the structural adjustment era (Ayee, 2001; Dodoo, 1997; Domfeh, 2004; Rhodes et al., 2012). However, the reforms under the Structural Adjustment regime failed to achieve its purpose in the civil service (Adei and Boachie-Danquah, 2003). In addition, the new public management (NPM) reforms were aimed at creating a performance culture in the 
public sector due to low performance of national development programs and economic reform initiatives in the country. Although these reforms were towards instilling a performance culture in the public service, it failed to yield the intended results for national development (Ohemeng, 2011).

PM in local governance in Ghana is relatively new and the driving force behind its introduction is to improve the use of public resources and service delivery at the local level. In tune with the notion of providing lower costs services to the grassroots, PM goals in the local government sector are to achieve the strategic framework of the decentralisation policy through a series of change management and performance-based system among local governments (Annan-prah and Ohemeng, 2015; LGS, 2016). To consolidate management and performance of local governments, the performance framework is tailored to make them efficient and effective in local service delivery (Akudugu, 2013). In keeping with the major objective of managing local government sector employees for development, a local PM framework was developed in 2015 with policy guidelines through the of setting KPAs for local governments. The effort of the new local government PM framework resulted in the assessment of MMDAs in four KPAs in 2016 (LGS, 2016). This represents the first real attempt at institutionalising PM in local governance through the signing of performance contracts of district chief executives and district directors.

\section{Methods}

The study analysed the performance results of 216 MMDAs in the local government sector using secondary data from recent performance evaluation results for local government authorities in the country. In addition, the study made use of the contents of annual reports of the LGS. The PM results of the various MMDAs were assessed to show the level of progress in institutionalising PM culture in local government authorities in Ghana. The secondary data consisted of two major reports from the LGS. To augment the two sources, the study used the 2012 PM policy for public services from the PSC database. The 2016 LGS Performance Evaluation results for 216 MMDAs form the main source of data for the study (See, table 1). The secondary data was used to assess their performance at the aggregate levels by focusing on four KPAs and their related performance indicators. The purpose of using secondary data sources was because these reports were the latest information and the first of its kind on local government PM assessment. Therefore, the reports provided enough evidence to answer the research questions posed in this study. The secondary data are presented in summary tables to help in the analyse. The use of secondary data as a primary source of analysis is important when the study involves large populations for which primary data collection may be difficult in undertaking (Hakim, 1982; Babbie, 2013). According to Hakim, using secondary data for re-analysis helps to develop new knowledge which is different from the original data (Hakim, 1982). Besides, the principal sources of information for this study helped to answer the research questions posed and they served as credible data on local governments performance in the country. Nevertheless, the use of secondary data has its limitations because the study had less control over the quality of the data collected.

The results suggest that MMDAs overall performance on the four KPAs was generally 


\section{Macrothink}

International Journal of Human Resource Studies

ISSN 2162-3058

2017, Vol. 7, No. 3

satisfactory, however, there are several challenges facing local governments' ability to achieve their performance goals. Resource constraints, low commitment of chief executives, directors and poor attitudes of staff affected the performance of some MMDAs. Also, low capacity and qualified personnel were some of the impediments which affected MMDAs performance rating of specific KPAs. The analysis revealed that some of these challenges are likely to thwart the gains and the outcomes of the PM policy at the local level in managing human resources for national development in the country.

Table 1. Data sources

\begin{tabular}{|l|l|l|l|}
\hline Type of Data & $\begin{array}{l}\text { Date of release of } \\
\text { Data }\end{array}$ & $\begin{array}{l}\text { Source of } \\
\text { Data }\end{array}$ & $\begin{array}{l}\text { How Data was } \\
\text { treated }\end{array}$ \\
\hline $\begin{array}{l}\text { Performance Evaluation Results of } \\
\text { MMDAs }\end{array}$ & 2016 & LGS & $\begin{array}{l}\text { Principal primary } \\
\text { data }\end{array}$ \\
\hline $\begin{array}{l}\text { Two Annual performance reports of } \\
\text { MMDAs }\end{array}$ & 2015 and 2016 & LGS & Supporting data \\
\hline $\begin{array}{l}\text { Public Service Performance Management } \\
\text { Policy }\end{array}$ & 2012 & PSC & Supporting data \\
\hline
\end{tabular}

\section{Results and Data Analysis}

The performance evaluation results were the first of its kind based on 2015 performance contracts between the LGS and MMDAs (LGS, 2015). The data contained in this research was obtained from LGS annual report for 2015, performance evaluation results for 2016 and the 2012 PM policy for the public service. The results showed improved performance of MMDAs in four KPAs in the country as mandated by the Local Government Act 462, 2003 (LGS, 2015). The results of 216 MMDAs performance evaluation showed significant progress in overall performance rating. However, the four KPAs showed sharp variations. 


\section{Macrothink \\ International Journal of Human Resource Studies \\ ISSN 2162-3058 \\ 2017, Vol. 7, No. 3}

Table 2. KPAs and KPIs of MMDAs

\begin{tabular}{|c|c|c|c|}
\hline KPA1 & KPA2 & KPA3 & KPA4 \\
\hline $\begin{array}{l}\text { Specific-Institution } \\
\text { Outputs and } \\
\text { Deliverable } \\
\text { Indicators }\end{array}$ & $\begin{array}{l}\text { Performance } \\
\text { Reporting }\end{array}$ & $\begin{array}{l}\text { Implementation of } \\
\text { Annual Action Plan and } \\
\text { Financial Management }\end{array}$ & $\begin{array}{l}\text { Human Resource } \\
\text { Management }\end{array}$ \\
\hline \multicolumn{4}{|c|}{ KPIs for each KPA } \\
\hline - KPIs Varies & 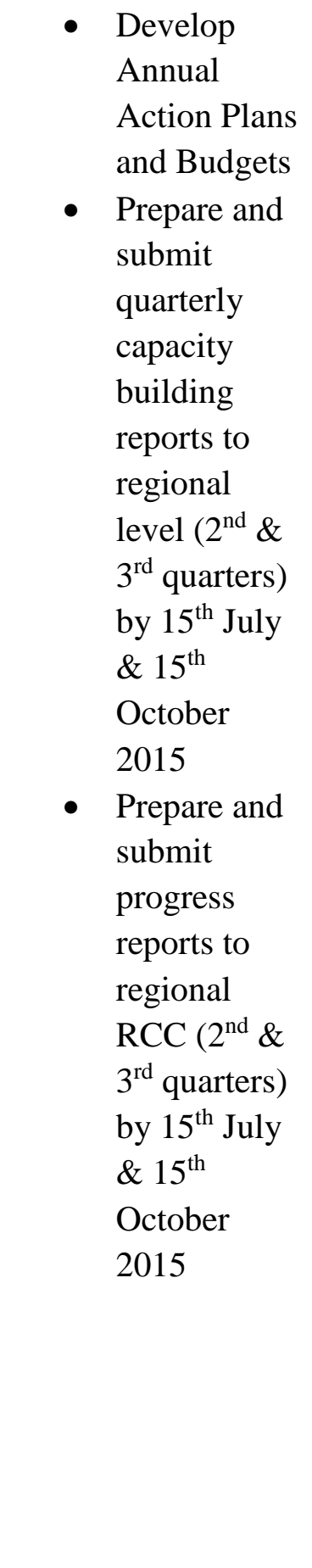 & $\begin{array}{l}\text { Accurately } \\
\text { record and } \\
\text { follow-up on all } \\
\text { actions taken by } \\
\text { audit Reports } \\
\text { Implementation } \\
\text { Committee } \\
\text { (ARIC) } \\
\text { quarterly } \\
\text { queries by } 15^{\text {th }} \\
\text { July \& October } \\
\text { 2015 } \\
\text { Develop and } \\
\text { approve } 2016 \\
\text { Annual } \\
\text { Procurement } \\
\text { Plan by } \\
\text { November } 2015 \\
\text { Ensure } \\
\text { completion of at } \\
\text { least } 80 \% \text { of } \\
\text { activities in the } \\
\text { Annual Action } \\
\text { Plan by } 31^{\text {st }} \\
\text { December } 2015 \\
\text { Ensure } \\
\text { implementation } \\
\text { of at least } 60 \% \\
\text { of annual } \\
\text { capacity } \\
\text { building } \\
\text { interventions by } \\
31^{\text {st }} \text { December } \\
\text { 2015 }\end{array}$ & 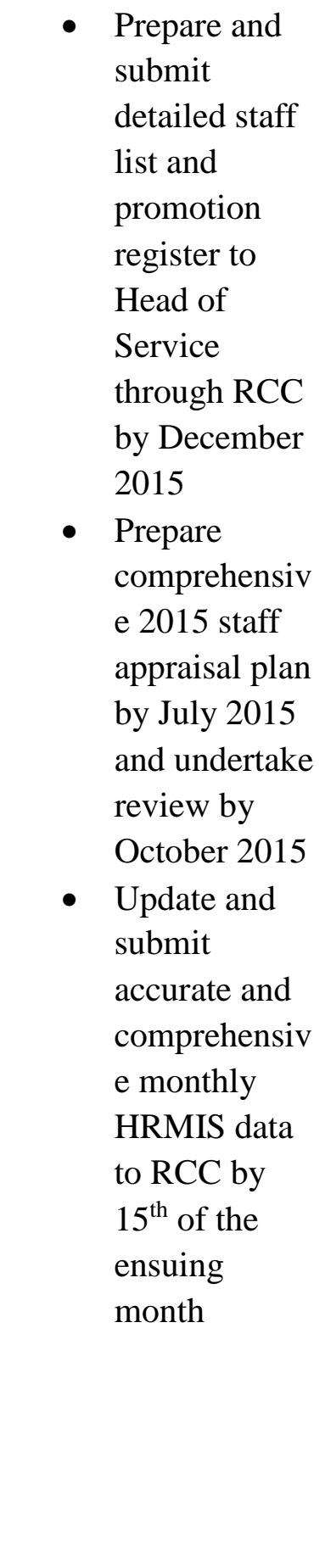 \\
\hline
\end{tabular}

Source: Adapted from LGS (2016) Performance Evaluation Results for MMDAs 


\section{Macrothink}

International Journal of Human Resource Studies

ISSN 2162-3058

2017, Vol. 7, No. 3

The results indicate that 116 districts obtain above average performance, 97 exceeded their targets, 3 obtained low- performance scores in the overall rating (LGS, 2016). The scoring was based on 'excellent' (80-100\%), 'very good' (70-79\%), 'good' (60-69\%), 'unsatisfactory' (59\% and below). See table 3 for MMDAs' performance rating.

Table 3. Overall Performance Rating of MMDAS

\begin{tabular}{|l|l|l|}
\hline Performance Rating & $\begin{array}{l}\text { Number of } \\
\text { MMDAs }\end{array}$ & $\begin{array}{l}\text { Percentage of Performance Ranking } \\
(\%)\end{array}$ \\
\hline Excellent & 116 & 53.7 \\
\hline Very Good & 72 & 33.3 \\
\hline Good & 25 & 11.6 \\
\hline Unsatisfactory & 3 & 1.4 \\
\hline Total & 216 & 100 \\
\hline
\end{tabular}

Source: Adapted from LGS (2016) Performance Evaluation Results for MMDAs

Additionally, in terms of the type of local government authority, the results indicate that the six metropolitan assemblies achieved most of their KPAs and indicators with four of the six obtaining above 80 percent in their overall rating. Of the fifty-four (54) municipal councils, 38 scored 'excellent', 13 obtained 'very good' and 3 scored 'good'. The indication is that most of the metropolitans and municipals assemblies perform better due to their relative size, resource-endowed and the qualified staff that these two types of local government authorities have over other types. Another trend observed is that the remaining 156 district assemblies which are small but may have more resource endowment than some municipal assemblies, 74 of them scored above 80 percent, 58 scored between 70-79 percent and 21 obtained between 60 and 69 percent points. However, 3 of these assemblies obtained unsatisfactory performance. The poor performance of these three local governments is reported to include, external factors which affect assemblies' ability to generate revenue locally, small staff strength and high attrition rate of employees who are posted to these assemblies. In addition, the reason for the low performance of the assemblies included low capacity of staff especially senior management in organisational management skills which affected their general operations and duties (LGS, 2015a, 2016: see table 4)

Table 4. Type of MMDAs and their Performance Rating

\begin{tabular}{|l|l|l|l|l|l|}
\hline Type & Excellent & Very Good & Good & Unsatisfactory & Total \\
\hline Metropolitans & 4 & 1 & 1 & 0 & 6 \\
\hline Municipalities & 38 & 13 & 3 & 0 & 54 \\
\hline Districts & 74 & 58 & 21 & 3 & 156 \\
\hline Total MMDAs & 116 & 72 & 25 & 3 & 216 \\
\hline
\end{tabular}

Source: Adapted from LGS (2016) Performance Evaluation Results for MMDAs

The results for four KPAs (KPAs) showed sharp difference among MMDAs. The results for 
KPA1suggests each MMDA had their specific targets and focus areas. However, MMDAs were to meet the minimum conditions of District Development Fund (DDF) and Functional Organisational Assessment Team (FOAT) guidelines. For instance, MMDAs were to improve their internally generated funds (IGF), establish functional decentralised departments and provide socioeconomic infrastructure and services. The purpose of this KPA is to allow for local level participation and for local government authorities to pay special attention to specific need areas in the districts. Most of the MMDAs performed satisfactorily on this KPA because the flexibility is in line with the decentralised planning which forms the major strategic focus of the country's decentralisation policy (Ayee, 2001). The evidence suggests that 53.2 percent obtained above average performance, 24.1 percent obtained average performance, 14.4 percent scored relatively good while, 8.3 percent performance were rated as unsatisfactory (See table 5 below)

Table 5. KPAs Results for MMDAs

\begin{tabular}{|l|l|l|l|l|}
\hline $\begin{array}{l}\text { Performance } \\
\text { Rating }\end{array}$ & $\begin{array}{l}\% \\
\text { MMDAs of } \\
\text { (KPA1) }\end{array}$ & $\begin{array}{l}\% \text { of MMDAs } \\
\text { (KPA2) }\end{array}$ & $\begin{array}{l}\% \\
\text { MMDAs(KPA3) }\end{array}$ & $\begin{array}{l}\% \text { of } \\
\text { MMDAs } \\
\text { KPA4) }\end{array}$ \\
\hline Excellent & 53.2 & 40.7 & 3.2 & 62.0 \\
\hline Very Good & 24.1 & 18.1 & 17.1 & 23.2 \\
\hline Good & 14.4 & 31.9 & 27.8 & 8.3 \\
\hline Unsatisfactory & 8.3 & 9.3 & 51.9 & 6.5 \\
\hline Total & 100.0 & 100.0 & 100.0 & 100.0 \\
\hline
\end{tabular}

Source: Adapted from LGS (2016) Performance Evaluation Results for MMDAs

Another trend observed in the results showed that KPA2 had three indicators and the 216 MMDAs perform relatively on the average. The indicators included action planning, budget preparation and quarterly submission of reports to the regional coordinating units who are responsible for monitoring and evaluating districts under their jurisdiction. Of the 216 districts, only 40.7 percent exceeded their targets, 50 percent achieved their targets and 9.3 percent perform below expectations (See table 5 above).

Further, the performance on KPA3 was relatively poor with the four KPIs under this KPA namely, implementation of audit reports and queries as recommended by the Audit Report Implementation Committees (ARIC) of MMDAs, a comprehensive annual procurement plan and completion of annual action plans by at least 80 percent of activities. In addition, the KPA indicators also mandated MMDAs to implement at least 60 percent of annual capacity building interventions by end of the year. From the results, 3.2 percent of them exceeded their targets. While most MMDAs perform poorly on this target with 51.9 percent performing below average (See table 5). According to the LGS (2016), the low performance on this KPA is attributed to inadequate audit staff and poorly constituted ARIC members of some MMDAs. It was observed that fewer of them could implement their audit queries while most of them failed to implement audit recommendations as contained in the Public Financial Management Regulations for local councils (LGS, 2016). 
Lastly, the fourth KPA had four indicators and majority of the MMMDAs perform commendably well except for some fourteen MMDAs whose performance on the indicator was below average. The weight of this indicator was $25 \%$ towards the overall performance of the three other KPAs. The implication is that most MMDAs human resource management systems were on course as most of the duties and functions of local government authorities are more of managing human resources and this may explain why this KPA seemed to have been achieved by most of the MMDAs (93.5 percent: see table 5 above). Another observation made by the reports note that most district directors and chief executives support for the human resource management of their districts explains the high score on that KPA.

\subsection{Challenges of PM of MMDAs}

The results of the performance evaluations of MMDAs revealed several challenges facing local government authorities. The results note that the challenges facing MMDAs PM are funding problems, low commitment from senior management staff, poor attitudes of staff, inadequate involvement of other staff members in the content of performance contracts (LGS,2016). However, three major challenges are most central. The challenges are irregular and insufficient budgetary allocations, low commitment of chief executives, directors and non-involvement of staff in the implementation of performance contracts and capacity building issues and training (LGS, 2016).

First, the findings reveal that MMDAs have limitations in meeting their targets on revenue generation, especially deprived districts. Also, the resource allocation from the central government is irregular and inadequate to implement their annual action plans. For most MMDAs, the delay and insufficient DACF and the DDF allocation by the central government affected their programmes during the performance evaluation period, thereby most of them could not achieve their targets. In addition, the delays in statutory funds impacted negatively on their annual budgets and procurement plans. This means that deprived districts could do little with insufficient IGF they generated to support their action plans. The implication is that deprived districts budgets are thrown overboard in the absence of central government assistance (Heinrich,2007; Ohemeng, 2011; LGS, 2016). Despite this limitation, some MMDAs could achieve their revenue targets.

Second, the results reveal some KPIs were affected low commitment and poor attitudes of chief executives, directors and their staff (LGS, 2016). This challenge is attributed to the lack of understanding of the PM contracts and little involvement of staff in the implementation process by senior management. Also, it was observed that some MMDAs chief executives were less committed to the PM policy of their institutions which resulted in low-performance outcomes. This finding has been found by similar studies that low commitment and poor attitudes of employees PM objectives have negative consequences (Pollitt Bouckaert, 2004; Waal and Counet, 2009; Karuhanga, 2010). Closely related to low commitment is the lack of involvement of other staff who are not made aware of the performance agreements signed by senior management of their assemblies. The inference is that most of the staff may have limited interest in the PM process which inform their poor response to performance targets (LGS, 2016). 
Third, another trend in the findings is that MMDAs were faced with low capacity issues which affected their KPIs. Although the results showed that most of the MMDAs had achieved their KPIs, some MMDAs were uniquely challenged by low capacity in the setting of clear performance indicators and technical competencies to implement key programmes and recommendations of the ARIC (LGS, 2016). This is because most of the MMDAs management staff had low level of training and competencies on organisation development, conflict and record management skills, information communication technology (ICT) skills and knowledge of performance appraisal systems (Akudugu, 2013; Bawole et al., 2013; Kroll and Moynihan, 2015). The issues of low capacity and competencies revealed that a handful of the MMDAs could meet the quarterly requirement of ARIC recommendations and laws governing auditing laws under the Local Government Act, 462. Besides, most MMDAs could not have full compliments of Audit staff to timely implement audit queries and reports (LGS, 2016). The low level of training among some MMDAs may have a huge impact on the quality of staff and their competencies in achieving PM objectives and long-term performance of local government bodies.

\subsection{Discussion}

The preceding sections, analyse the secondary data descriptively by focusing on four KPAs of MMDAs and the challenges that impede their KPIs toward the first-ever performance evaluation in local governance. The results demonstrate how MMDAs have implemented their performance contracts by developing KPIs to link with the objectives of the local government PM policy. While the results suggest an improvement in MMDAs performance in the four key areas, several challenges confront them in their effort to institutionalise a PM culture in local governance. Among other things, the challenges include, funding problems and budgetary constraints, low commitment and poor attitude of senior managers and their staff towards their performance indicators as well as the non-involvement of staff. Additionally, the results reveal that low capacity and competencies of staff affected some MMDAs overall performance.

However, the findings illustrate that PM is earnest and could be used as an alternative tool for local level management of public officers. Given that PM may be an alternative tool for managing MMDAs performance is seriously limited due to the challenges, the study recognises that similar studies have provided evidence to support that local and central government agencies PM policies are not without these challenges ( Fryer et al., 2009; Conaty, 2012; Ohemeng, 2011; Rhodes et al., 2012; Kim and Kang, 2016). And Ghana's experience is not unique and efforts to address these challenges may change the face of local level management in the country.

The findings indicate that some MMDAs PM systems are more effective than others and they tend to performance better (Ohemeng, 2009). This implies that while PM may be a tool to ensure high-performance culture among MMDAs, some local government authorities may not have the same level of capacity to succeed in this regard (Fryer et al., 2009) due to technical and resource limitations (Ohemeng, 2011) to institutionalise PM in their internal business process (Cavalluzzo and Ittner, 2004; Ter Bogt, 2008; Brignall and Modell, 2000). 
For instance, three MMDAs failed to achieve their performance indicators and the overall rating for these districts are below expectations. One of the reasons given for the abysmal performance is due to technical competencies and the deprived nature of these districts (LGS, 2016). The insufficient resource allocation such as the DDF and the DACF did impede MMDAs to meet 80 percent of their annual action plans. For those MMDAs who could not generate enough internal funds were seriously affected by the irregular flows of these resources (Akudugu, 2013; Mmieh et al., 2011; Heinrich, 2007).

Furthermore, the findings have highlighted the overrated assumption that PM outputs involve strategic planning, development of clear goals and performance targets as the most important deliverables in the process of institutionalising performance culture (Ammons and Roenigk, 2015; Caillier,2014; Latham et al., 2008). While these outputs were developed well and are relevant in the PM process, the important inputs for a successful policy on performance are the implementation stage in which impediments as the results revealed, can work negatively against local government performance policies. This implies that while goal setting and planning is necessary, it is important to support MMDAs with adequate resources such as financial resources, human resources and capacity building (Heinrich, 2007; Newcomer, 2007; Kroll Moynihan, 2015).

The evidence presented in this study also raises questions about whether local government authorities should have a wholesale KPAs set for them by the LGS. The current PM system does not take the unique characteristics of the 216 MMDAs into account because their resource endowment and capacities levels are remarkably different. That is should the three KPAs be used across the board without considering the size, resource generating ability and the quality of human resources of MMDAs? Even though wholesale institutionalisation is cheaper and simple, the evidence suggests that some MMDAs may need more support in these areas to be able to achieve their PM goals. If these seeming problems are not addressed by the central government and LGS by providing financial, technical and human resources to them, the current local government sector PM may fail to achieve its intended goals (Dodoo, 1997; Ohemeng, 2011; Hoontis and Kim, 2012; Koike, 2013; Annan-prah and Ohemeng, 2015).

More so, PM involves the management of teams and aligning individual to organisational goals (Armstrong and Baron,1998; Bourne, 2005). However, the results of this study indicate some of the MMDAs directors and chief executives failed to involve other staff in the implementation of the district's performance management policy. Clearly, this evidence contradicts PM planning strategy as presented in the public service PM policy (PSC, 2012) and adopted in 2015 by the LGS. With the institutionalisation of PM in local governance, three strategies can be observed from the policy. The first is strategic orientation which integrates employees' performance to the strategy of MMDAs, the second is human resource management which provides personnel information through the human resource management information system (HRMIS) to evaluate and appraise performance (PSC, 2012; LGS,2015). And third is a developmental approach which seeks to provide information on the strength and weaknesses of MMDAs for future performance improvement programmes (LGS, 2015). Despite these guidelines for MMDAs, the results suggest low commitment levels and 
involvement of staff in the implementation process (LGS, 2016).

Notwithstanding, these challenges, the results have reechoed that PM is an important tool for holistic management of local resources, creating value and closing the national development gap at the local level. The report for 2016 MMDAs performance evaluation indicates that most MMDAs excelled in the overall rating of the four KPAs, thereby improving their performance. From the results, the human resource management KPA, one significant observation is that almost all MMDAs perform satisfactorily because local government authorities are familiar with human resource management issues and the change management workshops organised for HR officers in the last two years (Annan-prah and Ohemeng, 2015). Meanwhile, 6.5 percent of MMDAs could not achieve this target. The report notes that the 6.5 percent could not assess their subordinates' performance and most supervisors failed to undertake mid-year review. The major stumbling block for some MMDAs who fared poorly is due to capacity-related issues and financial constraints because MMDAs who perform below average are deprived districts.

In the analysis, the results have two implications for institutionalising PM in local governance in the country. First, it is imperative for government and regulatory agencies to consider these unique differences that exist among MMDAs to reflect the KPAs that are set for adoption by local government authorities. Unless these contextual differences are addressed, the desire goals for instituting performance culture at the local level may be a mirage as previous experience shows (Ayee, 2001; Adei and Boachie-Danquah, 2003; Domfeh, 2004). Even if MMDAs adopt them it may impact on their internal management process (Brignall and Modell, 2000; Cavalluzzo and Ittner, 2004; Nurkholis et al., 2014). Second, technical competencies may be required by senior managers and their subordinates to fully develop clear and measurable performance indicators and train supervisors on how to use the performance ratings and scoring system (Bawole et al., 2013; Kroll and Moynihan, 2015).

In ending this discussing, the study notes that the findings may have implications for further studies. While the results reveal that resource constraints and irregular release of statutory funds, low capacity and technical competencies, affect MMDAs KPIs, this may need further research to discover whether resource endowment and low capacity do impact on PM goals. Also, low commitment levels of chief executives, directors and poor attitude of staff towards their KPIs require further studies. This is necessary because this was the first -time performance evaluation of MMDAs was conducted and this might have accounted for their poor behaviour. Future studies may examine the relationship between resource endowment and MMDAs performance on the four KPAs using surveys and case studies to find out how these factors affect their performance.

\section{Conclusion}

The purpose of this study was to assess the progress and challenges that affect MMDAs PM at the local level. Specifically, the study examined four KPAs of the PM policy for local government authorities. The performance results revealed several challenges and constraints of MMDAs performance goals. The study found that most MMDAs excel in three of the KPAs with 98.6 percent achieving their KPIs and 1.4 percent failed to obtain satisfactory 
performance in overall rating. Additionally, there were variations across the four areas, KPA4 obtained the highest percentage score (62.0 percent see table 6) while KPA3 obtained the lowest performance.

There are several challenges facing local government authorities PM objectives ( Lamothe, 2004; Fryer et al., 2009; Kim and Kang, 2016). This study demonstrated that institutionalising PM in government agencies are constrained by resource allocation, low commitment and capacity of organisational members to achieve their KPIs timely. Though PM may be considered as an alternative to local governance management in the context of developing countries development agenda, these impediments need to be addressed before any useful performance culture could be achieved in the long-run. The potential of PM to increase service quality and efficient use of resources by MMDAs should focus on setting outcome-based performance indicators because the KPIs only address the technical aspect of their responsibilities (Kim and Kang, 2016) while targets which assess their service quality to the public are less emphasised. This suggests that there is the need for MMDAs to improve their KPIs by including qualitative measures which relate to their end services to the public. The findings of this study have implications for further studies. First, the results revealed that resource constraints are affecting MMDAs ability to achieve their performance indicators and therefore, future studies should focus on establishing whether resource allocation or constraints do have an impact on performance indicators of MMDAs. Second, there is a need for further research on low commitment and capacity of senior managers on PM goals to discover if these factors have a link with the low performance of MMDAs. However, the use of secondary data in this study may have limitations since the data collected by Local Government Service might have an inherent bias on the four key performance areas and this could have implications for future research.

\section{References}

Adei, S. \& Boachie-Danquah, Y.(2003). The civil service performance improvement programme (CSPIP) in Ghana: Lessons of experience. African Journal of Public Administration and Management, 14(1), pp.10-23.

Aguinis, H., Joo, H. \& Gottfredson, R.K. (2012). Performance management universals: Think globally and act locally. Business Horizons, 55(4), pp.385-392. Available at: http://dx.doi.org/10.1016/j.bushor.2012.03.004.

Akudugu, J.A. (2013). Inducing Local Government Performance in Ghana: the Case of the District Development Facility. International Journal of Asian Social Science, 3(6), pp.1402-1417.

Ammons, D.N. \& Rivenbark, W.C. (2008). Factors influencing the use of performance data to improve municipal services: Evidence from the North Carolina Benchmarking Project. Public Administration Review, 68(2), pp.304-318.

Ammons, D.N. \& Roenigk, D.J. (2015). Performance Management in Local Government: Is Practice Influenced by Doctrine? Public Performance \& Management Review, 38(3), pp.514-541. Available 
http://www.tandfonline.com/doi/abs/10.1080/15309576.2015.1006461.

Annan-prah, E. and Ohemeng, F.L.K. (2015). Improving Productivity through Performance Management in Public Sector Organizations in Ghana : Is Change Management the Answer? Lecturer and PhD Candidate Department of Management Studies School of Business College of Humanities and Legal Studies Univer. In Birmingham.

Armstrong, M., \& Baron, A. (1998). Performance Management: The New Reallistic., London: Institute of Personnel and Development

Ashdown, L.(2014). Performance Management, London: Kogan Page.

Ayee, J.R.A. (2001). Civil Service Reform in Ghana: A Case Study of Contemporary Reform Problems in Africa. African Journal of Political Science, 6(1), pp.1-41.

Babbie, E. (2013). The Practice of Social Research 13th ed., Canada: WadsWorth, Cengage Learning.

Baird, Kevin \& Schoch, Herbert \& Chen, Q. James. (2012). Performance management system effectiveness in Australian local government. Pacific Accounting Review, 24(2), pp.161-185.

Bawole, J.N. et al. (2013). Performance Appraisal or Praising Performance? The Culture of Rhetoric in Performance Management in Ghana Civil Service. International Journal of Public Administration, 36(13), pp.953-962. Available at: http://www.tandfonline.com/doi/abs/10.1080/01900692.2013.773030.

Biron, M., Farndale, E. \& Paauwe, J. (2011). Performance management effectiveness: lessons from world-leading firms. The International Journal of Human Resource Management, 22(6), pp.1294-1311.

Ter Bogt, H.J. (2008). Recent and Future Management Changes in Local Government: Continuing Focus on Rationality and Efficiency? Financial Accountability Management, 24(1), pp.31-57. Available at: http://onlinelibrary.wiley.com/doi/10.1111/j.1468-0408.2008.00442.x/full.

Bouckaert, Geert \& Halligan, J. (2008). Managing Performance: International Comparisons, New York: Routledge.

Bourne, M. et al. (2014). Emerging issues in performance measurement. Management Accounting Research, 25(2), pp.117-118. Available at: http://dx.doi.org/10.1016/j.mar.2013.07.002.

Bourne, M. (2005). Researching performance measurement system implementation: the dynamics of success and failure. Production Planning \& Control, 16(2), pp.101-113.

Brignall, S. \& Modell, S. (2000). An institutional perspective on performance measurement and management in the "new public sector." Management Accounting Research, 11(June 1999), pp.281-306. Available at: http://www.sciencedirect.com/science/article/pii/S1044500500901367. 


\section{Macrothink}

International Journal of Human Resource Studies

ISSN 2162-3058

2017, Vol. 7, No. 3

Caillier, J.G. (2014). Does Public Service Motivation Mediate the Relationship between Goal Clarity and both Organizational Commitment and Extra-Role Behaviours? Public Management Review, 9037(February 2015), pp.1-19. Available at: http://www.tandfonline.com/doi/abs/10.1080/14719037.2014.984625.

Cavalluzzo, K.S. \& Ittner, C.D. (2004). Implementing performance measurement innovations: evidence from government. Accounting, Organizations and Society, 29(3-4), pp.243-267. Available at: http://linkinghub.elsevier.com/retrieve/pii/S0361368203000138.

Christensen, T., Lægreid, P. \& Stigen, I.M. (2006). Performance Management and Public Sector Reform: The Norwegian Hospital Reform. International Public Management Journal, 9(2), pp.113-139. Available at: http://www.tandfonline.com/doi/abs/10.1080/10967490600766987.

Conaty, F.J. (2012). Performance management challenges in Hybrid NPO/public sector settings: an Irish case. International Journal of Productivity and Performance Management, 61(3), pp.290-309.

DiMaggio, P. J and Powell, W.W. (1983). The Iron cage Revisited : Institutional Isomorphism and Collective Rationality in Organizational Fields. American Sociological Review, 48(2), pp.147-160.

Dodoo, R. (1997). Performance standards and measuring performance in Ghana. Public Administration and Development, 17(1), pp.115-121. Available at: http://doi.wiley.com/10.1002/(SICI)1099-162X(199702)17:1\%3C115::AID-PAD908\%3E3.0. $\mathrm{CO} ; 2-\mathrm{P}$.

Domfeh, K.A. (2004). Managing the environment in a decade of administrative reforms in Ghana. International Journal of Public Sector Management, 17(7), pp.606-620. Available at: http://www.emeraldinsight.com/10.1108/09513550410562275\%5Cnhttp://www.emeraldinsig ht.com/journals.htm?articleid=868047\&amp;show=abstract.

Van Dooren, W. (2011). Better Performance Management. Public Performance \& Management Review, 34(3), pp.420-433.

Favero, N., Meier, K.J. \& O'Toole, L.J. (2016). Goals, Trust, Participation, and Feedback: Linking Internal Management with Performance Outcomes. In Journal of Public Administration Research and Theory.

Fryer, K., Antony, J. \& Ogden, S.( 2009). Performance management in the public sector. International Journal of Public Sector Management, 22(6), pp.478-498. Available at: http://www.emeraldinsight.com/doi/abs/10.1108/09513550910982850.

Grizzle, G.A. (2002). Performance Measurement and Dysfunction: The Dark Side of Quantifying Work. Public Performance \& Management Review, 25(4), pp.363-369.

Hakim, C. (1982). Secondary analysis in social research: A guide to data sources and methods with examples, Unwin Hyman: Allen and Unwin. 


\section{$\triangle$ Macrothink}

Hammerschmid, G., Van de Walle, S. \& Stimac, V. (2013). Internal and external use of performance information in public organizations: results from an international survey. Public Money \& Management, 33(4), pp.261-268. Available at: http://www.tandfonline.com/doi/abs/10.1080/09540962.2013.799803.

Heinrich, C.J. (2007). Evidence-Based Policy and Performance Management. The American Review of Public Administration, 37(3), pp.255-277. Available at: http://arp.sagepub.com/content/37/3/255.abstract.

Hoontis, P. \& Kim, T. (2012). Antecedents to Municipal Performance Measurement Implementation. Public Performance \& Management Review, 36(1), pp.158-173.

Hvidman, U. \& Andersen, S.C. (2014). Impact of performance management in public and private organizations. Journal of Public Administration Research and Theory, 24(1), pp.35-58.

Karuhanga, B.N. (2010). Challenges of Performance Management in Universities in Uganda. Service Management, (August), pp.24-27.

Kim, Yoon and Kang, M. (2016). The Performance Management System of the Korean Healthcare Sector: Development, Challenges, and Future Tasks. Public Performance \& Management Review, 24(1), pp.297-315.

Koike, O. (2013). Institutionalizing performance management in Asia: looking East or West? International Journal of Public Sector Management, 26(5), pp.347-360. Available at: http://www.emeraldinsight.com/doi/abs/10.1108/IJPSM-05-2013-0066.

Kroll, Alexander and Moynihan, D.P. (2015). Does Training Matter? Evidence from Performance Management Reforms. Public Administration Review, 75(3), pp.411-420.

Kroll, A. \& Proeller, I. (2013). Controlling the control system: performance information in the German childcare administration. International Journal of Public Sector Management, 26, pp.74-85. Available at: http://www.scopus.com/inward/record.url?eid=2-s2.0-84872973696\&partnerID=tZOtx3y1.

Lamothe, M. (2004). Issues of contract implementation and management: The case of performance contracting in Florida human services. International Review of Public Administration, 4659(January). Available at: http://www.kapa21.or.kr/data/data_download.php?did=1468.

De Lancer Julnes, P. (2006). Performance Measurement: An Effective Tool for Government Accountability? The Debate Goes On. Evaluation, 12(2), pp.219-235.

Latham, G.P., Borgogni, L. \& Petitta, L.(2008). Goal Setting and Performance Management in the Public Sector. International Public Management Journal, 11(4), pp.385-403.

Lee, C.D. (2005). Rethinking the goals of your performance-management system. Employment Relations Today Wiley, 32(3), pp.53-60. Available at: http://simsrad.net.ocs.mq.edu.au/login?url=http://search.ebscohost.com/login.aspx?direct=tru 
e\&db=buh\&AN=18522874\&site=ehost-live.

Local Government Service. (2015). Annual Progress Report -2015, Accra.

Local Government Service. (2016a). Local Government Service 2015 Annual Performance Evaluation Report of Metropolitan, Municipal and District Assemblies ( MMDAs ), Accra.

Local Government Service. (2016b). Local Government Service 2015 Annual Performance Evaluation Report Of Regional Coordinating Councils ( Rccs ) 2015 Performance Contracts Between :, Accra.

Maley, J. (2014). Sustainability: the missing element in performance management. Asia-Pacific Journal of Business Administration, 6(3), pp.190-205. Available at: http://dx.doi.org/10.1108/APJBA-03-2014-0040.

Mmieh, F. et al.(2011). Performance Management in Public Sector Enterprises: A Case Analysis of Employees' Perceptions in the Electricity Company of Ghana (ECG). Journal of African Business, 12(July 2014), pp.419-438.

Moynihan, D.P. (2013). Advancing the Empirical Study of Performance Management: What We Learned From the Program Assessment Rating Tool. The American Review of Public Administration, 43(5), pp.499-517. Available at: http://arp.sagepub.com.proxy1.ncu.edu/content/43/5/499.abstract.

Moynihan, D.P. \& Lavertu, S. (2012). Does Involvement in Performance Management Routines Encourage Performance Information Use? Evaluating GPRA and PART. Public Administration Review, 72(August), pp.592-602.

Moynihan, D.P. \& Pandey, S.K. (2010). The big question for performance management: Why do managers use performance information? Journal of Public Administration Research and Theory, 20(4), pp.849-866.

Newcomer, K.E. (2007). Measuring Government Performance. International Journal of Public Administration, 30(3), pp.307-329.

Nurkholis, Sani Mohamad, M.H. \& Ismail, S. (2014). The effect of regulation and goal orientation on performance measurement utilisation: Evidence from Indonesian local governments. Asian Journal of Business and Accounting, 7(1), pp.81-105.

Ohemeng, F.L.. (2011). Institutionalizing the Performance Management System in Public Organizations in Ghana. Public Performance \& Management Review, 34(4), pp.467-488.

Ohemeng, F.L.K. (2009). Constraints in the Implementation of Performance Management Systems in Developing Countries: The Ghanaian Case. International Journal of Cross Cultural Management, 9(1), pp.109-132.

Oliver, C. (1991). Strategic Responses to Institutional Processes. Source: The Academy of Management Review, 16(1), pp.145-179. Available at: http://www.jstor.org/stable/258610\%5Cnhttp://www.jstor.org/stable/258610?seq=1\&cid=pdfreference\#references_tab_contents\%5Cnhttp://about.jstor.org/terms. 


\section{Macrothink}

International Journal of Human Resource Studies

ISSN 2162-3058

2017, Vol. 7, No. 3

Pollitt, C., \& Bouckaert, G. (2004). Public management reform: A comparative analysis., USA: Oxford University Press.

Public Services Commission. (2012). Performance Management Policy for the Public Services of Ghana, Accra.

Radin, B.A. (2006). Challenging the Performance Movement, Washington D.C: Georgetown University Press.

Rhodes, M.L. et al. (2012). Current state of public sector performance management in seven selected countries. International Journal of Productivity and Performance Management, 61(3), pp.235-271.

Rogers, S. (1990). Performance Management in Local Government, UK: Longman.

Sanderson, I. (2001). Performance Management, Evaluation and Learning in "Modern" Local Government. Public Administration, 79(2), pp.297-313. Available at: http://dx.doi.org/10.1111/1467-9299.00257.

Simpson, S. \& Buabeng, T. (2013). Performance Contract and Performance of Public Enterprises : A Study of the Implementation Processes. Journal of Public Administration and Governance, 3(2).

Taylor, A. \& Taylor, M. (2014). Factors influencing effective implementation of performance measurement systems in small and medium-sized enterprises and large firms: a perspective from Contingency Theory. International Journal of Production Research, 52(3), pp.847-866. Available at: http://dx.doi.org/10.1080/00207543.2013.842023.

Upadhaya, B., Munir, R. \& Blount, Y.(2014). Association between performance measurement systems and organisational effectiveness. International Journal of Operations and Production Management, 34(7).

Waal, A. A. De \& Counet, H. (2009). Lessons learned from performance management systems implementations. International Journal of Productivity and Performance Management, 58(4), pp.367-390.

Yang, K. \& Hsieh, J.Y. (2007). Managerial Effectiveness of Government Performance Measurement: Testing a Middle-Range Model. Public Administration Review, pp.861-879.

\section{Copyright Disclaimer}

Copyright for this article is retained by the author(s), with first publication rights granted to the journal.

This is an open-access article distributed under the terms and conditions of the Creative Commons Attribution license (http://creativecommons.org/licenses/by/4.0/). 